\title{
"One Multi Wing" Mode, The Private Colleges And Universities With Graduate Training Qualifications How To Improve Undergraduate
}

\author{
Jingfeng He, Guangzhen Zhang \\ College of Control Engineering, Xijing University, Xi' an 710123, China \\ 573825625@qq.com, 1136481611@qq.com
}

\begin{abstract}
Keywords: private university, Postgraduate training, one multi wing, training quality.
Abstract. This thesis is to study how to improve the quality of undergraduate education in private colleges and Universities under the "one multi wing" mode. Paper from the students' quality, teachers team construction, subject construction, training programs, such as the replacement of the credit started to study, this paper argues that "one wing" mode and research postgraduate education combine can improve the quality of undergraduate training, private colleges and universities in a healthy and harmonious, sustainable development has important practical significance.
\end{abstract}

\section{Introduction}

After the approval of the State Ministry of education, China's existing five universities have postgraduate qualifications, private colleges and universities first postgraduate education qualification, the move marks a private college degree level training to further improve, breaking the past graduate enrollment by public universities, research institutes, the exclusive monopoly situation.

Private schools to obtain graduate training qualifications of nature is the recognition of the quality of school running, but how to with graduate training in, to improve the quality of undergraduate teaching, private colleges and universities to obtain sustainable development is a very important topic. Xijing University in the proposed "integrated multi wing" mode, the graduate education and undergraduate education combined to improve the undergraduate teaching level, improve the quality of training.

\section{2. "One multi wing" training mode}

Application oriented personnel training goal orientation, and actively explore the new model of personnel training. Through years of exploration and practice gradually formed a "spirit of science, humanities literacy, professional expertise" of innovative talents training mode, and on this basis, and actively build to the personality education and "Science + art" as the guiding ideology of "one wing" talent training model. "One wing" talent training mode is through diversified construction, diversified and three-dimensional learning resource platform, for students to provide personalized, differentiated, customized education services, students to carry out the provisions of the contents of learning at the same time, a full range carry out selective, independent learning, to personalized learning and diverse culture, to achieve a strong professional ability, personality perfect, with personalized technology applied personnel training objectives.

"One wing" talent training mode to melt ability training and project teaching as a whole; by building a subject contest platform, the school enterprise cooperation platform, social practice platform,and actively expand the international exchange programs, create innovative entrepreneurship education practice base, and provide students with personalized, differentiated, customized education services, improve the student's comprehensive quality and employment ability of the, cultivating innovative applied talents for the practice of production, to meet the needs of society and enterprise.

"One multi wing" personnel training mode is shown in figure 1. 


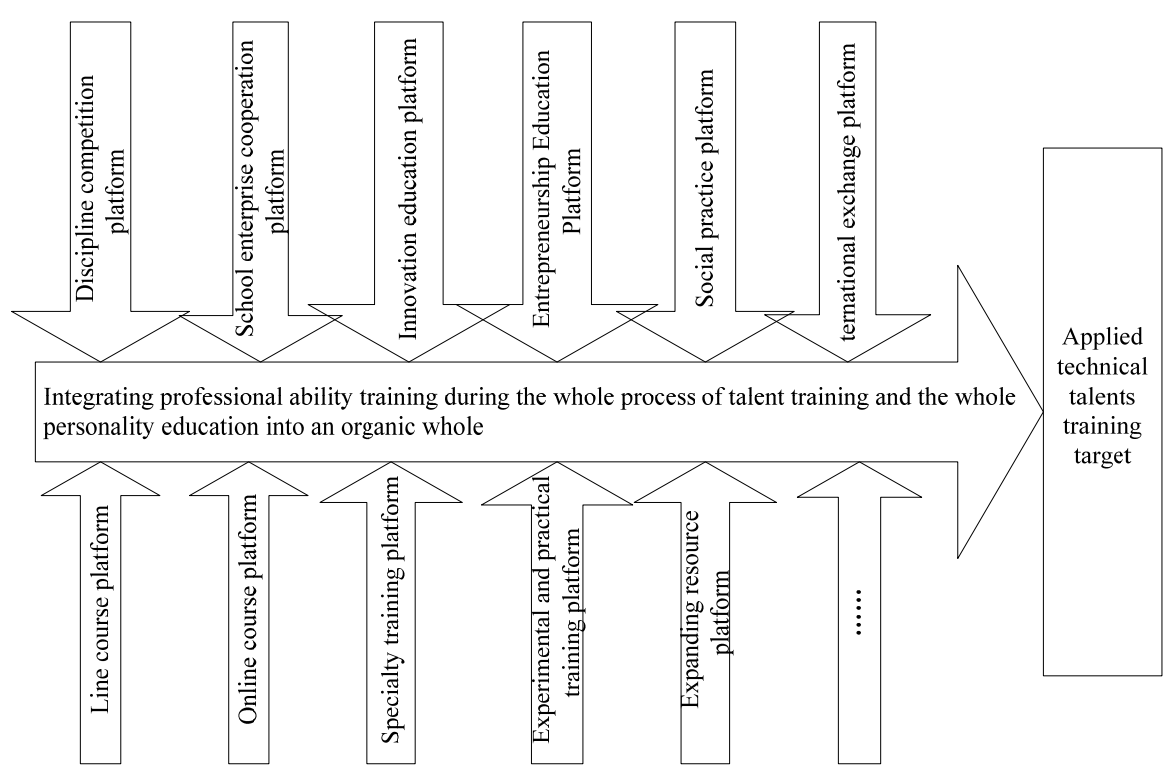

Figure 1 "One multi wing" training mode

\section{3. "One multi wing" mode, relying on graduate education, expand publicity to attract high quality students}

"Increasingly sad day", this is in recent years private colleges and Universities under the intensified competition for students under the weight of the difficult to survive the deepest feelings, even some private colleges and universities resorted to "do not look at the college entrance examination scores, generally put on notice" strategy. Private colleges and universities to carry out postgraduate education is the state on the basis of undergraduate education, for science and technology, culture, education and other professional training of senior specialized talents and the establishment of the highest level of education. Under China's current system, colleges and universities to culture students qualified for acquiring graduate students, in the school guiding ideology, material conditions, management, rules and regulations, the team of teaching and scientific research, discipline construction and the quality of education, scientific research foundation are put forward strict requirements. Under China's current system, colleges and universities to culture students qualified for acquiring graduate students, in the school guiding ideology, material conditions, management, rules and regulations, the team of teaching and scientific research, discipline construction and the quality of education, scientific research foundation are put forward strict requirements.Colleges and universities to carry out graduate education, make the level of talent training is complete, professional disciplines and curriculum system construction is reasonable, but also to meet the higher pursuit of college entrance examination.

"One multi wing" mode, private colleges and universities should rely on graduate education, expand publicity to attract more high-quality students to improve their educational level, after all, the quality of students directly affect the quality of training. Although not with public famous universities compete for students, but can still with has the advantage of graduate education, with public does not have a postgraduate training qualifications second-class school share part of the relative quality of the students. At least in the three colleges and universities to enroll more high-quality students, in order to improve the level of school to create conditions.

\section{One multi wing mode, relying on graduate education, to create a high level of teaching staff}

Postgraduate education is to cultivate high level professional talents. The development of postgraduate education has a positive effect on improving the level of teachers in a school or subject. First, the development of postgraduate education can promote the existing teaching staff to improve academic level and academic level. 
Secondly, the work of postgraduate education needs a highly educated, high titles of Postgraduate Tutor Team, therefore, in culture graduate will force the private colleges and universities through the introduction of culture to build high-quality teachers team.

Then the private colleges and universities have a platform for graduate training, and will also increase the attractiveness of high-quality teachers, high investment in graduate training can also retain a high level of talent. All graduate tutor and undergraduate teaching midstream mainstay. Therefore, private colleges and Universities Based on graduate education can create has a team of teachers with high quality.

"One multi wing" mode, the structure of teachers can be fully optimized, according to the interests of students to choose the teacher, so as to improve the quality of undergraduate teaching.

\section{5. "one multi wing" mode, relying on graduate education, to promote the discipline construction of undergraduate education}

The development of private colleges and universities from the point of view of the construction and development process of the professional point and the authorization point of the master's degree, Generally follow the undergraduate profession $\rightarrow$ improve $\rightarrow$ authorization is established to study the direction of widening $\rightarrow$ new undergraduate professional $\rightarrow$ improve $\rightarrow$ new authorization rules.

For a long period of time, even with the master, private colleges and public colleges and universities is still very difficult to compete. Postgraduate education colleges and universities, the key lies in the formation of their personality, in the service of regional economic efforts, to have its own characteristics. XiongBing Ji that the "Master of Applied Talents in Private Colleges is easy out of color. Some public high school tuition in the training of professional master's degree, but most of the curriculum 'new name', causing students and parents dissatisfied while time Master carried out not long, if at private colleges and universities to prepare the curriculum, teacher selection, etc., should be good prospects. "

Among the many colleges and universities to competition, discipline must start their own characteristics. Graduate education is a concentrated expression of the characteristics of this discipline. Improve graduate education for the development of specialized disciplines to provide a solid foundation. Especially private colleges and universities should rely on graduate education platform, integrate resources and form their own characteristics, culture graduate from this entry point to proceed to determine the direction of disciplines must be different from public institutions, public institutions become irreplaceable role. Only in this way, private colleges and universities to find yourself another piece of the sky, its own development.

\section{6. "one multi wing" mode, "one multi wing" mode, relying on graduate education, to promote the improvement of undergraduate teaching quality}

"One multi wing" mode, the full use of graduate students to serve as a mentor to the characteristics of the work. Relying on graduate education to promote the improvement of undergraduate teaching quality.

Based on the graduate education, the undergraduate tutor team is formed by the tutor, which is responsible for the academic progress of the undergraduate students and the other related problems encountered in the course of the semester. Responsible for guiding the students to write and publish academic papers, guiding students to write applications for patents.

Undergraduate students to participate in the graduate student tutor or research topic, so that undergraduate students in the teacher's scientific research activities to get exercise, so that the overall quality of students to improve.

Relying on the graduate student education practice base, as an undergraduate student's visit, practice, practice base, so that undergraduate students in practice to find the problem, put forward the problem. At the same time to select some practice course or curriculum design, let the students give full play to their potential, let them according to the visits, fieldwork, encountered in the practice of 
the problems put forward their own solutions and ideas to practice. Select some good programs and ideas to make them continue to improve, as a graduation project, so as to improve the level of undergraduate students' graduation design.

\section{Under the mode of "one body multi wing", relying on the graduate education to expand the social influence, and promote the undergraduate employment}

"One wing" mode, civilian run colleges and universities through all kinds of competitions and postgraduate training, enhance the strength of their school, their ability to run a school has been recognized by the society and the parents of the students, from a large extent will promote college graduates employment work. At the same time, with the passage of time, private colleges and universities is to cultivate the professional degree graduate students to grow slowly as the unit of employment management backbone or the technical backbone, so in society has certain influence, also accumulated certain social resources to a virtuous circle of the school development, these companies can be as an undergraduate production practice and graduation practice, social practice to provide convenient conditions, work for undergraduate employment created good opportunity.

\section{Summary}

Adhere to the full personality education and the "science and art" of the guiding ideology, focusing on the comprehensive development of knowledge, ability and quality, pay attention to the general education and professional education "width", "thickness", "depth" of the coordination. With educating people as the fulcrum, actively carry out science and application innovation activities of college students, students through the subject contest to solve practical problems, the theoretical knowledge into practical ability. While stimulating the enthusiasm of the students to learn, it is clear that the goal of professional learning, and at the same time, the professional skills training.

In 2015, the Xijing university students to participate in the national mathematical modeling contest, the applied talents comprehensive skills contest, National English Contest for college students and other various competitions 170, including 103 above provincial and ministerial level competition, 1011 national awards, 697 provincial and ministerial level awards, a total of 1708. Annual competition of 13600 students number of visits, which 2508 have won provincial and ministerial level awards number, race and education realized transference of breakthrough.

\section{References}

[1] Gong Qiaoru, Ma Xiaohong. The relationship between undergraduate education and graduate education [J]. Journal of Zhuzhou Institute of Technology, 2002, 16 (6): 117-118.

[2] Chen Shiwei. From contradiction to coordination: the reasonable determination of the relationship between law undergraduate and graduate education in China -- to improve the judicial examination system in China [J]. Journal of Southwest University of Political Science and Law, 2012 (3): 126-130.

[3] Chen Tingzhu. Research on the connection between graduate education and undergraduate education [J]. degree and postgraduate education, 2001 (7): 32-34.

[4]Jian Jisong. On undergraduate and graduate goal of graduate education differences influence the education mode [J]. Contemporary education theory and practice, 2009, 1 (5): 93-94.

[5] Guo Shiyin, Lu Xiangyang, He Jianhua . The promoting role of graduate education in undergraduate education -- Taking Hunan Agricultural University as an example [J]. higher education of agriculture.2008-08,08:71-75

[6] Information on http://www.xijing.com.cn 